\title{
VARIABILIDADE ENTRE ISOLADOS DE Trichoderma harzianum. I - ASPECTOS CITOLÓGICOS
}

\author{
E. PERES; I.S. DE MELO \\ CNPMA/EMBRAPA, C.P. 69, CEP; $13820-000$-Jaguariúna,SP
}

\begin{abstract}
RESUMO: Objetivou-se neste trabalho estudar a variabilidade de isolados selvagens de Trichoderma harzianum baseado nas características culturais e citologicas. Observaram-se o tamanho dos fialosporos, número de núcleos por fialosporos e crescimento e esporulação em meio de malte-ágar. Pelos resultados aqui encontrados foi possível reconhecer que há variação entre os isolados selvagens da especie $T$. harzianum. Com relação ao número de núcleos, verificou-se uma variação de 1 a 3 núcleos por fialosporos. Também observou-se padrões diferenciais de crescimento e morfologia da colônia. Mais de $50 \%$ dos isolados atingiram o máximo de crescimento em 48 horas.

Descritores: Trichoderma harzianum, citologia, variabilidade
\end{abstract}

\section{VARIABILITY AMONG Trichoderma harzianum ISOLATES. I - CYTOLOGICAL ASPECTS}

\begin{abstract}
This study is based largely on morphological and cultural characters of Trichoderma harzianum isolates. It were observed the size of phialospores, mycelial growth and sporulation on malt extract agar and nuclei number per phialospores, stained with Giemsa. A $\times 100$ oil immersion len was used in examining and in measuring phialospores. Based on the size of phialospores, it was possible recognize that there is variaton among the wild isolates for the specie $T$. harzianum. Also, with relation to mycelial growth and sporulation can itself distinguish from one another different pattern. Up to $50 \%$ of isolates had maximum growth in 48 hours. The nuclei number of 1 to 3 per phialospore was observed.
\end{abstract}

Key Words: Trichoderma harzianum, citology, variability

\section{INTRODUÇÃO}

Trichoderma spp. é um fungo saprófita componente ativo da microflora do solo.

Como agente de biocontrole, pode proteger plantas contra patógenos de solo (COOK \& DAKER, 1983; PAPAVIZAS, 1985; CHET \& ELAD, 1983; MELO, 1991) e promover crescimento de plantas (WINDHAM et al.), através de um fator que regula o crescimento e germinação de sementes. O gênero tem sido estudado extensivamente como fonte potencial de celulases (MANDELS, 1975; SUM \& BROWN, 1976; STERNBERG, 1976). GHOSE \& GROSH (1979) sugerem que o sistema enzimático mais promissor para o processo de sacarificação da celulose cristalina é o de Trichoderma.

A taxonomia, a genética e composição da população de Trichoderma spp. não são ainda bem compreendidas e, portanto, são necessários métodos mais precisos para diferenciar linhagens de diferentes espécies para propósito de patente ou determinação da variabilidade de linhagens em ecossistemas naturais.

Isolados de T. harzianum têm diferido na sua capacidade de atacar certos fungos fitopatogênicos, tais como: Sclerotium rolfsii, Rhizoctonia solani e Pythium aphanidermatum (ELAD et al., 1982).

O presente trabalho relata a variabilidade natural de isolados selvagens de $\boldsymbol{T}$. harzianum quanto ao tamanho dos fialosporos, número de núcleos por fialosporos e taxa de crescimento e esporulação em meio de cultura.

\section{MATERIAIS E MÉTODOS}

\section{Isolados de $T$. harzianum}

Os isolados th. 1, th. 2 , th. 3 , th. 4 , th. 5 , th.6, th.7, th.8 e th.9, foram provenientes do CNPAF/EMBRAPA em Goiânia, GO e os isolados 
Tal-1, Tal-8 e Tma-4, do solo do Estado de São Paulo e o Th-95 foi isolado na Colômbia e tem sido estudado extensivamente nos Estados Unidos como antagonista ao fungo Rhizoctonia solani, cedido por Dr. R. Baker (Colorado University, USA).

\section{Crescimento Micelial e Conidiação}

A variabilidade no crescimento apresentada pelos isolados foi verificada através da medida do diâmetro das colônias, crescidas em meio de BDA (batata, dextrose e ágar), com 24 e 48 h após inoculação de um disco de meio BDA contendo conídios jovens no centro de cada placa de Petri. As culturas foram incubadas a $30^{\circ} \mathrm{C}$ no escuro.

Para determinar a quantidade de conídios produzidos pelos isolados, 3 discos de 1 $\mathrm{cm}$ de diâmetro foram retirados de cada colônia no $5^{\circ}$ dia de crescimento e colocados em $3 \mathrm{ml}$ de solução de Tween 80 a $0,1 \%$ para desagregação dos mesmos através da agitação. A contagem direta dos conídios foi efetuada em câmara de Neubauer, sob microscópio óptico.

\section{Coloração de Núcleos de Conídios}

Os isolados de $T$. harzianum foram incubados por 72 horas, em meio de Aveia-Ágar, a $30^{\circ} \mathrm{C}$. Os conídios formados foram aderidos à laminulas contendo albumina a $50 \%$ e fixados durante 30 minutos em etanol: ácido acetico (3:1). A seguir os conídios aderidos foram fixados durante $5 \mathrm{~min}$. em álcool $95 \%$ e depois $20 \mathrm{~min}$. em álcool 70\%. O material foi lavado 3 vezes em água destilada e hidrolizado em $\mathrm{HCl} 1 \mathrm{~N}$ à $60^{\circ} \mathrm{C}$ durante $7 \mathrm{~min}$. Lavou-se por mais 3 vezes consecutivas em água destilada e uma vez em solução tampão fosfato $\mathrm{pH} \mathrm{6.9}$. O material foi corado com $1 \mathrm{ml}$ de solução de Giemsa e $9 \mathrm{ml}$ de tampão fosfato $\mathrm{pH}$ 6.9 por $30 \mathrm{~min}$.

O diâmetro dos conídios foi estimado com auxílio de ocular micrométrica Carl Zeiss $4892628(8 x)$ em objetiva de 100x.

\section{RESULTADOS E DISCUSSÃO}

\section{Crescimento e Esporulação}

Trichoderma é um fungo de crescimento rápido. Daí a grande vantagem de utilização como agente de biocontrole em larga escala. A
TABELA 1 mostra que, dos 12 isolados, 7 atingiram o crescimento máximo em 48 horas. Há, portanto, uma variação na taxa de crescimento entre os isolados, principalmente, nas primeiras 24 horas de crescimento a $30^{\circ} \mathrm{C}$. $O$ isolado Th-95, usado com sucesso no biocontrole, tem um crescimento mais lento comparado aos demais isolados, assim como apresenta uma taxa mais baixa de esporulação. Nem todos os isolados que apresentaram crescimento mais rápido correspondem àqueles com maior esporulação, mesmo Th-2, Th-3, Th-4 e Th-8 que apresentam esporulação na periferia da placa.

Os isolados Th-2, Th-8, Th-95 e Tma-4 quando crescidos em BDA descolorem o meio com a produção de substâncias metabólicas de coloração que varia de amarelo claro ao marrom.

$\begin{array}{ll}\text { TABELA 1 - } & \text { Variação no crescimento } \\ \text { micelial e esporulação em } \\ \text { isolados selvagens de } T . \\ \text { harzianum. }\end{array}$

\begin{tabular}{lllr}
\hline & \multicolumn{2}{c}{$\begin{array}{c}\text { Crescim. Micelial } \\
\text { (cm) }\end{array}$} & $\begin{array}{r}\text { Esporulação' } \\
\text { (x 107 esporos) }\end{array}$ \\
\cline { 2 - 3 } ISOLADOS & & \\
\cline { 2 - 3 } & 24 horas & 48 horas & \\
\hline Th.1 & 6,39 & 9,00 & 8,294 \\
Th.2 & 4,12 & 9,00 & 1,485 \\
Th.3 & $\mathbf{8 , 0 1}$ & 9,00 & 1,076 \\
Th.4 & 6,67 & 9,00 & 0,610 \\
Th.5 & 3,83 & 9,00 & 7,563 \\
Th.6 & 2,89 & 7,27 & 6,857 \\
Th.7 & 2,89 & 9,00 & 2,544 \\
Th.8 & 5,23 & 9,00 & 1,261 \\
Th.95 & 2,37 & 6,48 & 0,171 \\
Tal.1 & 2,59 & 7,14 & 8,369 \\
Tal.8 & 2,62 & 6,79 & 1,407 \\
Tma.4 & 2,17 & 7,53 & 0,567 \\
\hline
\end{tabular}

'Esporulação após 48 horas. Média de 4 repetições

\section{Tamanho de Conídios}

Os esporos de $T$. harzianum são ovóides ou globosos. Verifica-se que o tamanho dos mesmos varia em diferentes isolados (TABELA 2), de 2,53 um a 4,23 um, apesar de muitos destes serem provenientes do solo da mesma região, como é o caso dos isolados Th.1, Th.2, Th.3, Th.4, Th.5, Th.6, Th.7 e Th.8. De acordo com a 
taxonomia de espécies de Trichoderma, RIFAI (1969) descreve que os esporos de T. harzianum variam de 2,4-3,2 um $\times 2,2-2,8$ um, com uma média em torno de 3,0 × 2,7 um. Descrições feitas para isolados do solo em Sheffild, Inglaterra.

0 isolado Th. 1 , com comprimento médio de 4,23 e largura de 3,72 um pode ser uma outra espécie de Trichoderma, pois não se inclui na chave de taxonomia do Gênero, feita por Rifai. As espécies $T$. longibrachiatum e $T$. pseudokoningii, apresentam esporos maiores, $\operatorname{com} 3,6-6,5 \times 2,2$ x 30 um e $3,4-4,6 \times 2,0-5,0$ um, respectivamente (RIFAI, 1969).

Estudos mais aprofundados sobre características morfológicas de outras estruturas do fungo precisam ser feitos; assim como a utilização de técnicas modernas de biologia molecular, como polimorfismo de DNA de diferentes linhagens de diferentes espécies, no sentido de elucidar e distinguir com certa segurança espécies de gênero Trichoderma.

TABELA 2- Variação no comprimento e largura de conídios em isolados selvagens de T. harzianum.

\begin{tabular}{|c|c|c|c|c|c|c|}
\hline \multirow{2}{*}{ ISOLAI } & \multicolumn{3}{|c|}{$\begin{array}{l}\text { Compr. de Conídios } \\
\text { (um) }\end{array}$} & \multicolumn{3}{|c|}{$\begin{array}{l}\text { Largura de Conídios } \\
\quad \text { (um) }\end{array}$} \\
\hline & & $s$ & c.v. & $\mathrm{X}$ & $S$ & C.V. \\
\hline Th. 1 & 4,2316 & 0,6430 & 15,1965 & 3,7205 & 0,5621 & 18,1080 \\
\hline Th.2 & 2,6671 & 0,4389 & 16,4561 & 2,3766 & 0,3297 & 13,8733 \\
\hline Th. 3 & 3,1573 & 0,5783 & 18,3167 & 2,5911 & 0,4421 & 17,0643 \\
\hline Th. 4 & 3,9932 & 0,6486 & 16,2429 & 2,9502 & 0,4090 & 13,8639 \\
\hline Th.5 & 2,8593 & 0,4892 & 17,1108 & 2,4912 & 0,4586 & 18,4113 \\
\hline Th. 6 & 3,4121 & 0,5098 & 14,9413 & 2,8459 & 0,3726 & 13,0916 \\
\hline Th. 7 & 2,9204 & 0,5366 & 18,3742 & 2,6000 & 0,4794 & 18,4372 \\
\hline Th. 8 & 2,5330 & 0,4925 & 17,7360 & 2,3319 & 0,3767 & 16,1541 \\
\hline Th.95 & 2,8608 & 0,5575 & 19,4878 & 2,4883 & 0,5211 & 20,9430 \\
\hline Tal.1 & 3,4196 & 0,4882 & 14,2763 & 3,0232 & 0,2481 & 8,2081 \\
\hline Tal.8 & 3,6669 & 0,5506 & 15,0150 & 2,9696 & 0,1775 & 5,9776 \\
\hline Tma.4 & 2,7330 & 0,4573 & 16,7338 & 2,7327 & 0,4571 & 16,7252 \\
\hline
\end{tabular}

\section{Número de Núcleos por Conídio}

Houve diferanças entre os isolados estudados quanto ao número de núcleos em cada conídio da espécia T. harzianum. Em geral, todos os isolados mostraram maior proporção de conídios uninucleados, apesar de 8 isolados (Th.1, Th.3, Th.4, Th.5, Th-95, Tal.11, Tal.8 e Tma.4) apresentarem conídios com dois núcleos e, destes, os isolados Th.3, Th.5, Th.95, Tal.11 e Tal.8, com três núcleos (TABELA 3). O número médio básico de núcleos deve ser usado para estudo taxonômico, que deve ser incrementado nesta espécie, além de outros parâmetros como variação isoenzimática, cujos resultados serão publicados posteriormente.

A coloração com Giemsa permitiu uma boa visualização dos núcleos. O pequeno tamanho destes não permitiu a mensuração dos mesmos. Sobre estes aspectos não se dispõe de dados na literatura para comparar tais resultados. Em T. pseudokoningii, FURLANETO (1989) tem mostrado que esta espécie apresenta esporos uninucleados. Segundo NEVALAINEN (1985) os conídios de $T$. reesei são haplóides e uninucleados, como também estes estudos têm revelado a presença de no mínimo quatro cromossomos grandes.

Linhagens que apresentam elevado números de núcleos por célula mostram desvantagens em relação àquelas com poucos núcleos quanto a alta variabilidade que apresentam, assim como a grande dificuldade de obter mutantes estáveis. No presente estudo, verifica-se que a espécie $T$. harzianum é primordialmente, uninucleada.

TABELA 3 - Variação no número de núcleos por conídios em isolados selvagens de $T$. harzianum.

\begin{tabular}{|c|c|c|c|}
\hline \multirow{2}{*}{$\begin{array}{l}\text { ISOLADOS } \\
\text { uninu }\end{array}$} & \multicolumn{3}{|c|}{ \% de Conídios } \\
\hline & uninucleados & binucleados & trinucleados \\
\hline Th.1 & 96 & 4 & - \\
\hline Th.2 & 100 & - & - \\
\hline Th.3 & 81 & 16 & 3 \\
\hline Th.4 & 99 & 1 & - \\
\hline Th.5 & 63 & 21 & 16 \\
\hline Th.6 & 100 & - & - \\
\hline Th.7 & 100 & - & - \\
\hline Th. 8 & 100 & - & - \\
\hline Th.95 & 43 & 24 & 33 \\
\hline Tal.1 & 72 & 17 & 11 \\
\hline Tal.8 & 60 & 30 & 10 \\
\hline Tma.4 & 87 & 13 & - \\
\hline
\end{tabular}

\section{REFERÊNCIAS BIBLIOGRÁFICAS}

CHET, I.; ELAD, Y. Mechanism of mycoparasitism. Les Colloques of L'INRA, Paris, v.18, n. 35-40, 1983. 
COOK, R.J.; BAKER, K.P. The nature and practice of biological control of plant pathogens. St. Paul: American Phytopathological Societs, 1983. p.539.

ELAD, Y.; CHET, I.; HENIS, Y. Degradation of plant pathogenic fungi by Trichoderma harzianum. Canadian Journal of Microbiologis, Ottawa, v.28, p.719-725, 1982.

FURLANETO, M.C. Recombinação genética e produção de celuloses em trichoderma pseudokoningii var. RIFAI. Piracicaba, 1989. 152p. Dissertação (Mestrado) - Escola Superior de Agricultura "Luiz de Queiroz", Universidade de São Paulo.

GHOSE, T.K.; GHOSH, P. Celulose production and cellulose hydrolysis. Process Biochemistry, London, v.1, p.14, 1979.

MANDELS, M. Microbiol sources of cellulases. In: WIKE C.R. (Ed.) Cellulose as a chemical and energy resource. New York: John Wiley, 1975. p.81-105.

MELO, I.S. Potencialidades de utilização de Trichoderma spp. no controle biológico de doenças de plantas. In: BETTIOL, W. (Org.) Controle biologico de doenças de plantas. Brasília: EMBRAPA, 1991, p. 388 .

NEVAILANEN, H. Genetic improvemant of enzyme production in industrially important fungal strains. Helsinki, 1985. 243p. Thesis (PhD) - University of Helsinki).
PAPAVIZAS, G.C. Trichoderma and Gliocládium: biology ecology, andd potencial por biological control. Annual Review of Phytopathology, Palo Alto, v.23, p.23-54, 1985.

RIFAI, M.A. A revision of the genus Trichoderma. Mycological Papers, Wallingford, v.116, p.1-56, 1969.

STERNBERG, D.B. Glucosidase of Trichoderma: its biosynthesis and role is sacharification of cellulose. Applied and Enrironmental Microbiology, Baltimore, v.31, p.648-654, 1976. 073

SUM, E.K.; BROWN, R.D. Strutural characterization of a glucoprotein cellulose. $1,4=\mathrm{b}=\mathrm{d}=$ glucam cellobiobydrolase $\mathrm{C}$ from Trichoderma viride. Biochimica et Biophysica, Amsterdam, v.446, p.371-386, 1976 .

WINDHAM, M.T.; ELAD, Y.; BAKER, R.A. A mechanism for increased plant growth induced by Trichoderma spp. Phytopathology, v.76, p.518-521, 1986.

Entregue para publicação em 16.06 .93

Aceito para publicação em 10.01 .95 